\title{
Principios de la comunicación efectiva en una organización de salud
}

\author{
Principles of the effective communication in a healthcare organization
}

\author{
Patrizio Petrone $\mathbb{D}$, MD, PhD, MPH, MHSA, MAAC, FACS \\ Coeditor, Revista Colombiana de Cirugía. Associate Professor of Surgery, NYU Long Island School of Medicine. \\ Director of Surgical Research. Program Director of the International Research Fellowship. Department of Surgery, \\ NYU Langone Hospital__Long Island, Mineola, New York, USA
}

\section{Introducción}

La comunicación es el proceso mediante el cual transmitimos y recibimos datos, ideas, opiniones y actitudes para lograr comprensión y acción. Etimológicamente proviene del latín communicare que se traduce como "poner en común, compartir algo". La comunicación es un elemento básico generador de sociabilidad. Es a través de ella que el hombre se nutre y preserva su carácter como ser eminente de convivencia, promueve la solidaridad social y el espíritu cooperativo entre los grupos.

El proceso de interacción en el que se comparte la información es breve y descriptivo, ya que es un proceso de transmisión de información, de un emisor a un receptor, a través de un medio. En la transmisión y la recepción de esa información se utiliza un código específico (palabras, gestos, símbolos), que deben ser codificados por el emisor y decodificados por el receptor.

En el ser humano la comunicación es un acto propio de su actividad psíquica, derivado del lenguaje y del pensamiento, así como del desarrollo y manejo de las capacidades psicosociales de relación con el otro. Permite al individuo conocer más de sí mismo, de los demás y del medio exterior, mediante el intercambio de mensajes, principalmente lingüísticos, que le permiten influir y ser influido por las personas que lo rodean. La comunicación es de suma importancia para la supervivencia de especies gregarias, pues la información que éstas extraigan de su medio ambiente y su facultad de transmitir mensajes serán claves en el entorno.

Otros elementos que componen el proceso de la comunicación incluyen el canal o medio físico

Palabras clave: organización de salud; comunicación; medios de comunicación; barreras de comunicación; comunicación no verbal; principios; cultura organizacional.

Keywords: healthcare organization; communication; communications media; communication barriers; nonverbal communication; principles; organization \& administration.

Fecha de recibido: 23/10/2020 - Fecha de aceptación: 03/11/2020 - Fecha de publicación en línea: 12/02/2021

Correspondencia: Patrizio Petrone, Department of Surgery, NYU Langone Hospital_Long Island, 222 Station Plaza North, Suite 300; Mineola, New York, 11501, USA. Teléfono: +1 (516) 663-9571.

Correo electrónico: patrizio.petrone@gmail.com y patrizio.petrone@nyulangone.org

Citar como: Petrone P. Principios de la comunicación efectiva en una organización de salud. Rev Colomb Cir. 2021;36:188-92. https://doi.org/10.30944/20117582.878

Este es un artículo de acceso abierto bajo una Licencia Creative Commons - BY-NC-ND https://creativecommons.org/licenses/by-nc$\mathrm{nd} / 4.0 /$ deed.es 
de comunicación (carta, teléfono, televisión, internet), el ruido o las distorsiones que pueden influir en la recepción del mensaje, y la retroalimentación o feedback, que es la respuesta del receptor hacia el mensaje recibido. También tiene importancia el contexto, ya que tiene influencia directa en la interpretación del mensaje (espacio físico, marco de referencia cultural, contexto social).

Entre los principios más importantes se puede mencionar que en la comunicación de calidad no hay diferencias entre lo que el emisor quiere decir y lo que el receptor entiende. En la comunicación en general, y en el mundo profesional en particular, se considera que lo importante es lo que entiende el receptor, y no lo que el emisor quiere decir. Cuando un receptor no comprende un mensaje, o lo malinterpreta, posiblemente la causa está en la falta de claridad por parte del emisor. Para hacer más eficaz la comunicación, el emisor debe orientar el mensaje al receptor y a la respuesta que quiera obtener de él.

Uno de los conceptos de la comunicación afirma que es un proceso continuo y dinámico, formado por una serie de acontecimientos variados y sucesivos en interacción, con el fin de alcanzar los objetivos planteados. La esencia de una comunicación eficaz es la respuesta a esta serie de variables. No es posible el desarrollo humano individual si permanecemos mental, social o físicamente aislados. La comunicación no es solo una transferencia de información entre individuos, sino que ella debe ser clarificada y negociada por ambos, dado que pueden estar influenciados por numerosas variables, como por ejemplo la percepción, los valores, las creencias y los aspectos sociales, culturales y familiares.

Gracias a la comunicación es posible transmitir las experiencias de una generación a otra, para que puedan ser asimiladas y continuadas. El avance es posible ya que se trata de un proceso continuo de enseñanza y aprendizaje.

La comunicación puede ser dividida en verbal (palabra oral o escrita), no verbal, y asertiva.

La palabra escrita es uno de los medios de comunicación más antiguos de la humanidad. Es un método de intercomunicación humana que se realiza por medio de signos visuales que consti- tuyen un sistema. Es un proceso mecánico, una destreza psicomotriz mediante la cual se aprende a escribir palabras y oraciones, que permiten la materialización inteligible del mensaje. La comunicación escrita se caracteriza porque se puede revisar y eliminar errores antes de transmitirla, se puede archivar fácilmente, el receptor puede leer a su ritmo y revisar la información cuantas veces quiera. También es de feedback lento, suele ser más costosa (en tiempo y dinero), no se puede asegurar que su mensaje ha sido leído y su comunicación es más fría. Nos sirve para transmitir hechos, opiniones e información compleja, y dejar plasmado aquello que tiene que quedar por escrito.

La comunicación oral es más personal e individualizada, se puede adaptar sobre la marcha con base al feedback que se va recibiendo. Generalmente es menos costoso producirla, se puede apoyar en elementos no verbales, pero no se puede revisar, por lo que una vez dicho algo no se puede borrar, es efímera y de corta duración. Nos sirve para transmitir sentimientos y emociones, informaciones breves y sencillas y para comunicaciones de impacto.

Por su parte, la comunicación no verbal es todo proceso de intercambio de información en el que no es necesario el uso de palabras, ni orales ni escritas. Se subclasifica en tres tipos:

- Comunicación no verbal kinésica: se refiere al uso del lenguaje corporal (gestos, miradas).

- Comunicación no verbal proxémica: tiene que ver con la distancia entre una persona y otra, la cual varía según la circunstancia y la cultura. Por ejemplo, en Latinoamérica es normal que las personas estén muy cerca, pero en los países anglosajones esto puede interpretarse como una agresión o invasión del espacio personal.

- Comunicación no verbal paralingüística: se refiere a la expresión de sonidos sin palabras (gritos de euforia, bostezos, cambios de tono de voz).

Por último, está la comunicación asertiva, en la que el emisor logra expresar un mensaje de forma 
simple, oportuna y clara, considerando las necesidades del receptor o interlocutor. Asertividad es el arte de expresar de un modo directo y honesto lo que se piensa, desea o siente, a otra persona, mostrándole respeto. Se trata de una habilidad social importante asociada a la inteligencia emocional y a la comunicación no verbal.

\section{Axiomas de la comunicación}

El psicólogo Paul Watzlawick, uno de los pilares de la Teoría de la Comunicación, estableció los siguientes cinco axiomas:

$\checkmark \quad$ Es imposible no comunicarse.

$\checkmark$ Toda comunicación tiene un nivel de contenido y de relación.

$\checkmark \quad$ La naturaleza de una relación depende de la puntuación de las secuencias comunicacionales entre personas.

$\checkmark \quad$ La comunicación humana implica dos modalidades: la digital (lo que se dice) y la analógica (cómo se lo dice).

$\checkmark$ Los intercambios comunicacionales pueden ser tanto simétricos como complementarios.

Según Watzlawick, la realidad de cada ser humano es una interpretación construida por y a través de la comunicación, es decir construimos el mundo como pensamos que lo percibimos. Estos axiomas son esenciales para la interrelación entre dos sujetos, y son a su vez capaces de hacer fracasar la comunicación si alguno de ellos no funciona, ya que la comunicación es un proceso que ocurre de forma continua y en diferentes niveles.

La comunicación es la herramienta fundamental para el trabajo en equipo. Comunicarse efectivamente requiere escuchar a los demás desde su realidad y no desde la propia. Para ello es necesario desarrollar el pensamiento crítico que se convertirá en el instrumento que contribuirá a la comprensión del mensaje que se desea transmitir, y así poder analizar y evaluar lo dicho con una perspectiva más amplia.

Dialogar es el intercambio de ideas entre dos o más personas con el fin de producir beneficios de diversa índole. El diálogo implica la exposición de ideas, argumentándolas de manera sólida y deba- tiéndolas con el propósito de entender diferentes posturas, mediante la escucha y comprensión de los mensajes de otros.

\section{Comunicación organizacional}

La comunicación organizacional es el conjunto de acciones, procedimientos y tareas que se llevan a cabo para transmitir o recibir información a través de diversos medios, métodos y técnicas de comunicación, interna y externa, con la finalidad de alcanzar los objetivos de la organización.

A través de la comunicación organizacional se establecen estrategias de desarrollo, productividad y relaciones, internas y externas, a fin de obtener un mejor desempeño por parte del recurso humano, por lo que su finalidad se relaciona con los logros, éxitos o fracasos de la organización.

A su vez, la comunicación organizacional permite que los procesos internos de trabajo se desarrollen correctamente, exista un óptimo clima de trabajo y se alcancen los objetivos propuestos. La comunicación es una herramienta de vital importancia para establecer la gestión eficaz y eficiente de la organización.

\section{Tipos de comunicación organizacional Comunicación interna}

Se practica a través de la estructura de la organización y promueve el proceso de comunicación entre el personal, facilita su integración, fortalece su cohesión y contribuye a crear espacios para el intercambio de información.

\section{Comunicación externa}

Consiste en diseñar y transmitir información desde la organización hacia el público, comunidad o sociedad, a través de los diferentes canales de comunicación, con el objetivo de mantener las relaciones públicas. Dan a conocer los bienes que producen o servicios que prestan a través de publicidad, donaciones o patrocinio, se sostienen las relaciones con instituciones gubernamentales y mantienen las relaciones interinstitucionales, a fin de formalizar alianzas, desarrollar proyectos $o$ estrategias de mercado. 


\section{Comunicación escrita}

Se caracteriza por transmitir mensajes concretos y claros. A su vez proporciona un respaldo a la organización, ya que queda un registro o referencia de aquello que se comunica. Algunos ejemplos son los boletines internos, convocatorias, encuestas o memorandos.

\section{Comunicación oral}

Este tipo de comunicación se caracteriza porque existe la probabilidad de que la información no se comprenda completamente y se generen dudas o malentendidos. Puede ser formal al realizarse en una reunión, asamblea o conferencia, o informal, si es una conversación ocasional entre compañeros de trabajo.

Los procesos de comunicación permiten a la organización mantener la coordinación entre sus distintos estamentos y alcanzar así su característica esencial, la de ser un sistema. La acción coordinada y el trabajo en equipo contribuirán a lograr los objetivos estratégicos.

La comunicación además es un instrumento de transformación. El pensamiento estratégico lleva implícito un mensaje de adaptación al entorno variable de la organización. En este contexto, la comunicación interna permite la introducción, difusión, aceptación e interiorización de los nuevos valores y pautas de gestión que acompañan el desarrollo organizacional. La comunicación se convierte así en un factor de integración, motivación y desarrollo personal, como parte fundamental en la búsqueda de calidad.

\section{Flujos de comunicación Comunicación ascendente}

La información es aportada desde los niveles de jerarquía más bajos a las dependencias superiores. Esto es posible cuando se toma en cuenta la importancia de la comunicación que aportan los trabajadores como una forma de retroalimentación. Permite conocer el clima social de la organización, contribuye a estimular la creatividad de los trabajadores, favorece el enriquecimiento y desarrollo personal, facilita la cooperación entre los diferentes estamentos, aumenta el compro- miso con la organización y mejora la calidad de las decisiones.

\section{Comunicación descendente}

La información se transmite desde las altas jerarquías hacia los subordinados. Forma parte de la cultura organizacional de las empresas de autoridad centralizada. Se comunican las tareas u obligaciones según el orden de las demás dependencias y sus responsabilidades. Como contrapartida, antepone los intereses de la organización y descuida el nivel socio-integrativo. La ambigüedad y la imprecisión aparecen como síntomas de futuros conflictos.

\section{Comunicación horizontal o cruzada}

Es la que se establece entre miembros que tienen niveles de jerarquía similares. Se caracteriza por transmitir la información con mayor rapidez, coordinar actividades, solucionar problemas o tomar decisiones específicas.

\section{Barreras de la comunicación organizacional}

Muchas organizaciones deben sus logros o fracasos a la comunicación organizacional. Por tal razón, es muy importante comunicar y transmitir información clara y precisa, que esté al alcance de todos y que llegue a través de los diferentes canales de información. Sin embargo, existen diversas barreras en la transmisión de la información, que se pueden originar en el emisor, en un mensaje confuso, en el receptor o en la retroalimentación de la información, por ejemplo:

- Transmitir información confusa, poco precisa o ambigua.

- Distorsionar el mensaje a medida que se va transmitiendo por los diversos canales de comunicación.

- Perder información por parte de quienes la comunican.

- Ofrecer información innecesaria.

- Fallas de las herramientas tecnológicas.

- Barreras de contexto internacional: idioma o expresiones culturales. 


\section{Reglas básicas en la comunicación organizacional}

La comunicación organizacional es de vital importancia para llevar a cabo la gestión de una organización. Es un intercambio constante de información que permite desarrollar métodos o dar solución a la actividad que se lleve a cabo, para prestar un bien o un servicio de calidad.

La experiencia dicta que utilizar bien el lenguaje ayuda a evitar conflictos verbales, a deshacer malentendidos y a facilitar bien-entendidos. Las reglas de la comunicación organizacional incluyen:

$\checkmark \quad$ Ser educados, entendiendo por educación tratar a todos con el mismo respeto y cortesía. Todos los trabajos son importantes y necesarios.

$\checkmark \quad$ Valorar el tiempo y el esfuerzo invertido en una acción. Abre puertas y deja buena impresión. La utilización de las palabras por favor y gracias pueden obrar milagros. Las normas de cortesía facilitan las aperturas y los cierres de conversaciones.

$\checkmark$ Ayudar a la mejora de la calidad del producto o servicio y del buen ambiente laboral.

$\checkmark \quad$ Respetar los tiempos. Ante una situación de conflicto centrémonos en la solución.

$\checkmark \quad$ Es de mala educación empeñarse en querer tener razón, básicamente por la pérdida de tiempo y recursos que conlleva.

$\checkmark \quad$ Es de buena educación encontrar soluciones y evitar conflictos laborales posteriores.

$\checkmark \quad$ Las situaciones deben presentarse de forma razonada y educada. Con ello se facilita el aprendizaje, la comprensión y el plan de acción a llevar a cabo.
Todos cometemos y hemos cometido errores. Normalmente éstos se dan por inexperiencia, ignorancia de impactos o desconocimiento de variables a tener en cuenta. El reto no es no cometerlos, sino aprender de ellos y convertirlos en experiencia para una siguiente ocasión.

Como decía Peter Drucker, "demasiados jefes piensan que son muy buenos en su trato con la gente porque hablan bien, y no se dan cuenta que ser bueno en el trato con la gente quiere decir escuchar bien".

\section{Desterrar las frases en negativo}

El peso de la frase se encuentra en la acción, el verbo. Focalizarse en la solución es más fácil al exponer los hechos. Se deben construir frases con verbos en afirmativo y decir lo que se desea de forma clara, directa y sencilla. Esta acción impactará facilitando el entendimiento y la comprensión con las personas que interactúan. De este modo se mejorará la eficiencia, entendiendo como tal hacer un buen trabajo en tiempo y costo óptimos.

La práctica de estas reglas economizará tiempo, evitando o previniendo conflictos, y ayudará a mejorar la calidad del servicio, facilitando la creación de un ambiente de trabajo motivado y profesional.

\section{Referencias recomendadas}

1. Katz D, Kahn R. Psicología Social de las Organizaciones. México: Trillas; 1983.

2. Watzlawick P, Beavin J, Jackson D. Teoría de la Comunicación Humana. Barcelona: Herder; 1983.

3. Luhmann N. Conciencia y Comunicación. En: La Ciencia de la Sociedad. México-Barcelona: U. Iberoamericana Anthropos; 1996.

4. PignuoliS. El modelo sintético de comunicación de Niklas Luhmann. Cinta moebio. 2013;47:59-73. https://doi.org/10.4067/S0717-554X2013000200001

5. Drucker P. The new realities: in government and politics, in economics and business, in society and world view. New York: Harper \& Row; 1989. 